\title{
POSITIVE SOLUTIONS TO A NONLINEAR SIXTH ORDER BOUNDARY VALUE PROBLEM
}

\author{
BO YANG
}

Abstract. We consider a sixth order two point boundary value problem. Upper and lower estimates for positive solutions of the problem are proved. Sufficient conditions for the existence and nonexistence of positive solutions for the problem are obtained. An example is included to illustrate the results.

Mathematics subject classification (2010): 34B15, 34B18.

Keywords and phrases: Sixth order boundary value problems, positive solutions, upper and lower estimates, Green's function.

\section{REFERENCES}

[1] M. M. Adjustovs AND A. J. LePINS, Extremal solutions of a boundary value problem for a sixthorder equation, Differ. Equ., 50, 2 (2014), 141-146.

[2] Ravi P. Agarwal, B. Kovacs, And D. O'Regan, Positive solutions for a sixth-order boundary value problem with four parameters, Bound. Value Probl., 2013, 184 (2013), 22 pages.

[3] Ravi P. Agarwal, B. Kovacs, AND D. O'REgan, Existence of positive solution for a sixth-order differential system with variable parameters, J. Appl. Math. Comput., 44, 1-2 (2014), 437-454.

[4] Abdulmalik Al Twaty and Paul W. Eloe, Concavity of solutions of a $2 n$-th order problem with symmetry, Opuscula Math., 33, 4 (2013), 603-613.

[5] J. V. Chaparova, L. A. Peletier, AND S. A. Tersian, Existence and nonexistence of nontrivial solutions of semilinear sixth-order ordinary differential equations, Appl. Math. Lett., 17, 10 (2004), 1207-1212.

[6] T. GARBUZA, On solutions of one 6-th order nonlinear boundary value problem, Math. Model. Anal., 13, 3 (2008), 349-355.

[7] SuQin Ge, WANYI WANG, AND QIUXIA YANG, Dependence of eigenvalues of sixth-order boundary value problems on the boundary, Bull. Aust. Math. Soc., 90, 3 (2014), 457-468.

[8] FAZHAN GENG AND YongGang Ye, Solving analytically singular sixth-order boundary value problems, Int. J. Math. Anal. (Ruse), 3, 37-40 (2009), 1945-1952.

[9] KaZem Ghanbari And Hanif MirZaei, On the isospectral sixth order Sturm-Liouville equation, J. Lie Theory, 23, 4 (2013), 921-935.

[10] JOHN R. GRAEF AND BO YANG, Boundary value problems for sixth order nonlinear ordinary differential equations, Dynam. Systems Appl., 10, 4 (2001), 465-475.

[11] T. GyULOV, Trivial and nontrivial solutions of a boundary value problem for a sixth-order ordinary differential equation, C. R. Acad. Bulgare Sci., 58, 9 (2005), 1013-1018.

[12] Tihomir Gyulov, Gheorghe Morosanu, and Stepan Tersian, Existence for a semilinear sixth-order ODE, J. Math. Anal. Appl., 321, 1 (2006), 86-98.

[13] Yude Ji, Yanping Guo, Yukun YaO, and Yinguie Feng, Nodal solutions for sixth-order $m$ point boundary-value problems using bifurcation methods, Electron. J. Differential Equations, 2012, 217 (2012), 18 pages.

[14] M. A. KRASNOSEL'SKIĬ, Positive solutions of operator equations, Noordhoff Ltd. Groningen, 1964.

[15] WANJUn LI, The existence and multiplicity of positive solutions of nonlinear sixth-order boundary value problem with three variable coefficients, Bound. Value Probl., 2012, 22 (2012), 16 pages. 
[16] WANJUn Li, LiYUAN ZHANG, AND YUKUn An, The existence of positive solutions for a nonlinear sixth-order boundary value problem, ISRN Appl. Math., 2012, (2012), Art. ID 926952, 12 pages.

[17] H. MIRZAEI, Existence and nonexistence of positive solution for sixth-order boundary value problems, Bull. Iranian Math. Soc., 42, 6 (2016), 1451-1458.

[18] MANFRed MÖLler AND BerTin Zinsou, Sixth order differential operators with eigenvalue dependent boundary conditions, Appl. Anal. Discrete Math., 7, 2 (2013), 378-389.

[19] Bo YANG, Upper estimate for positive solutions of the $(p, n-p)$ conjugate boundary value problem, J. Math. Anal. Appl., 390, 2 (2012), 535-548.

[20] LIYUAN ZHANG AND YUKUN AN, Existence and multiplicity of positive solutions of a boundaryvalue problem for sixth-order ODE with three parameters, Bound. Value Probl., 2010, (2012), Art. ID 878131, 13 pages. 